\title{
Direitos humanos a luz da agenda 2030 e plano clima energia 2050: o uso das energias renováveis em prol do meio ambiente
}

\author{
Priscila Elise Alves Vasconcelos ${ }^{1}$ \\ Cleyson de Moraes Mello ${ }^{2}$
}

\section{Resumo}

Em pleno ano de 2020 as discussões acerca da preservação ambiental passaram a ser prioridade, tanto no âmbito nacional como internacional. Em decorrência da pandemia que assolou o mundo - COVID 19 -, a busca de soluções para sobrevivência humana se tornaram verdadeiros desafios. Nessa linha, a pesquisa aborda o contexto do Acordo de Paris e do Plano Clima e Energia 2050 no âmbito do uso de energias renováveis. Para isso, a metodologia utilizada foi a qualitativa, com base em dados oficiais, políticas públicas atuais, doutrina especializada e artigos científicos extraídos de base de dados como Web of Science, Scopus e Google Acadêmico. Ao final, é possível verificar o impacto que a mudança comportamental em prol do consumo sustentável na área de energia elétrica pode influenciar na preservação e tutela do meio ambiente.

Palavras-chave: Sustentabilidade; Desafios; Energias renováveis; Pandemia.

\begin{abstract}
In the middle of 2020, discussions about environmental preservation became a priority, both nationally and internationally. As a result of the pandemic that has plagued the world - COVID 19 - the search for solutions for human survival have become real challenges. In this line, the research addresses the context of the Paris Agreement and the Climate and Energy Plan 2050 in the context of the use of renewable energies. For this, the methodology used was qualitative, based on official data, current public policies, specialized doctrine and scientific articles extracted from databases such as Web of Science, Scopus and Google Scholar. In the end, it is possible to verify the impact that behavioral change in favor of sustainable consumption in the area of electricity can influence the preservation and protection of the environment.
\end{abstract}

Keywords: Sustainability; Challenges; Renewable energies; Pandemic.

\footnotetext{
${ }^{1}$ Estágio Pós Doutoral em Direito das Cidades (UERJ). Doutora em Direito (UVA RJ). Mestra em Agronegócios (UFGD). Especialista em Meio Ambiente (COPPE UFRJ), Direito Público e Direito Privado (EMERJ ESA). Pesquisadora GGINNS. Bolsista Prosup Capes UVA. Premiada na categoria Direito Urbanístico e Meio Ambiente do Prêmio Livros pela obra "Função Socioambiental das Cidades: o uso de energia renováveis e a cogeração advinda de resíduos sólidos" em 2020. Professora da FADIR UFGD. Advogada.

2 Pós-Doutorado em Teoria do Direito no IHGB (2018); Doutor em Direito (2006); Coordenador do curso de Direito do UNIFAA; Professor Titular do UNIFAA; Vice-Diretor da Faculdade de Direito da UERJ; Professor do PPGD da UERJ e UVA. Membro do IAB.
} 


\section{INTRODUÇÃ̃}

2020 será marcado por um ano de grandes desafios. Com o surgimento de uma pandemia que assolou os continentes, com milhares de infectados e mortes, a temática Meio Ambiente voltou a ter seu destaque.

De acordo com vários estudos publicados ao longo do ano de 2020, a preservação ambiental se tornou uma verdadeira questão de sobrevivência. Houve uma valorização da educação ambiental e de busca pela conscientização para conservação e não degradação a fim de evitar novas pandemias. $O$ temor pelas perdas causadas passou a ser visto de forma positiva por aqueles que tanto lutam pelo Meio Ambiente.

Ao abordar a temática Meio Ambiente, é imprescindível destacar que está caracterizado como um Direito Humano de terceira geração ou dimensão. Numa visão sistêmica, é possível verificar que a aplicabilidade do princípio da dignidade a pessoa humana está diretamente relacionada à proteção ambiental.

Assim, a pesquisa a ser demonstrada tem por escopo abordar o meio ambiente no contexto dos tratados internacionais ocorridos a partir de 2015: a Agenda 2030 e o Plano Clima Energia de 2050.

Para tanto, a metodologia utilizada foi a análise de dados oficiais, artigos científicos extraídos das principais bases como Web of Science, Scopus e Google Acadêmico, além de doutrina nacional e estrangeira sobre o assunto. As políticas mundiais também foram imprescindíveis para o desenvolvimento da pesquisa.

Ao final da pesquisa, é possível verificar o quão relevante são as discussões acerca das políticas mundiais - com uma breve análise sobre as perspectivas pós-pandemia de COVID 19. Inclui-se a abordagem sobre o homem ser integrante do meio ambiente e que suas condutas refletem diretamente na preservação ambiental.

\section{O SER HUMANO COMO SER INTEGRANTE DO MEIO AMBIENTE}

O Meio Ambiente é formado por quatro aspectos: natural, artificial, cultural e do trabalho. Para Sirvinskas (2015), o meio ambiente natural abrange a fauna, flora, atmosfera, tudo o que estiver relacionado a recursos naturais. $O$ artificial engloba qualquer espaço construído. Já o cultural está relacionado a bens materiais e imateriais com valores paisagísticos, históricos, artísticos, arqueológicos, ecológicos e científicos. Por fim, o autor traz o meio ambiente do trabalho - ou laboral. Nesse, independente de ser remunerado ou não, as normas de seguranças são efetivamente consideradas.

Acerca da figura e participação do homem, de acordo com a Declaração das Nações Unidas de 1972 - Declaração de Estocolmo -, trata-se de parte integrante do meio ambiente 
(ONU, 1972). É reconhecido o aspecto natural e artificial do meio ambiente, imprescindíveis ao bem-estar da vida humana ${ }^{3}$.

Dausaku Ikeda (Athayde e Ikeda, 2018) aponta de forma clara que a Declaração Universal dos Direitos Humanos está alicerçada nos próprios seres humanos, fazendo com que a dignidade absoluta da vida humana seja inviolável, merecendo por isso ser preservado.

Diante disso, é preciso lembrar do artigo $1^{\circ}$., inciso III da Carta da República de 1988 (BRASIL, 1988). De acordo com o dispositivo constitucional, a dignidade da pessoa humana é princípio fundamental, sendo basilar do ordenamento jurídico brasileiro.

Inclusive, é de suma importância lembrar que desde o advento do Código Civil de 2002, a constitucionalização do Direito passou a ser uma realidade no Brasil. Junto, houve a valorização do meio ambiente e o aumento considerável na área de energias renováveis produção e consumo. Para Fiorillo (2016), esses fatores acrescidos dos tratados internacionais repercutiram na contextualização do princípio da dignidade da pessoa humana e sua relação com meio ambiente ecologicamente sustentável.

Cumpre lembrar que a Constituição da República de 1988 elencou o direito ao meio ambiente ecologicamente equilibrado como uma cláusula pétrea. Ou seja, está enquadrado como um dos princípios fundamentais do ordenamento jurídico brasileiro (VASCONCELOS, 2019).

\section{ENERGIAS RENOVÁVEIS NO SÉCULO XXI}

Durante muitos anos o desenvolvimento econômico esteve relacionado ao uso de combustíveis fósseis - carvão mineral, petróleo e derivados. Com a Revolução Industrial ocorrida no final do século XVIII, foi possível alcançar patamares antes utópicos no setor, repercutindo diretamente no avanço da sociedade.

Ao passar dos anos e com o impacto causado no meio ambiente pelo uso excessivo desses combustíveis, o resultado negativo da evolução foi o aquecimento global. Advindo das emissões de gases de efeitos estufa - GEE -, a busca por alternativas em reduzir o avanço desse aquecimento passou a ser o maior desafio em todo o mundo e objeto de discussões entre as mais diversas nações.

\footnotetext{
3 " 1 . Man is both creature and moulder of his environw ment, which gives him physical sustenance and affords him the opportunity for intellectual, moral, social and spiritual growth. In the long and tortuous evolution of the human race on this planet a stage has been reached when, through the rapid acceleration of science and technology, man has acquired the power to transform his environment in countless ways and on an unprecedented scale. Both aspects of man's environment, the natural and the manwmade, are essential to his well-being and to the enjoyment of basic human rights-even the right to life itself "(ONU, Report of the United Nations Conference on the Human Environment, 1972, page 08).
} 
No Brasil, as ações governamentais começaram a surgir nos anos 2000. Com a Lei $\mathrm{N}^{\circ}$ 10.295/2001, é publicada a Política Nacional de Conservação e Uso Racional de Energia. Através desse programa, a União Federal tinha por objetivo uma alocação eficiente dos recursos energéticos, além da preservação ambiental (BRASIL, 2001).

Posteriormente, em 2002, foi publicado o Programa de Incentivo às Fontes Alternativas de Energia Elétrica - PROINFA - através da Lei n ${ }^{\circ}$ 10.438/2002 (BRASIL, 2002). O objetivo principal passa a ser o fomento da participação da energia elétrica produzida por empreendimentos de produtores independentes e autônomos. Surge no contexto brasileiro a legitimação do prosumer ou autoprodutor de energia.

É interessante apontar que o PROINFA não estava destinado apenas a uma fonte de energia renovável. O programa engloba as fontes de energia eólica, pequenas centrais hidrelétricas e biomassa.

Em 2015, concomitantemente a realização do Acordo de Paris, ocorreu a COP 21. Nesse evento mundial, o Brasil foi reconhecido como o país campeão em energia limpa. Àquela época, segundo dados do CERNE (2015), as fontes renováveis correspondiam a aproximadamente $78 \%$ da energia gerada no Brasil. Esse percentual já superava em três vezes a média mundial, com $20,3 \%$ de fontes renováveis.

Em 2020, de acordo com dados extraídos do Ministério de Minas e Energia - MME o Brasil passa a ter uma maior participação das fontes diversas à hidrelétrica em sua matriz energética (mais abrangente). Através de três indicadores ${ }^{4}$ - crescimento do consumo das famílias, renovabilidade e segurança -, foi possível constatar um aumento de $0,6 \%$ no uso de fontes renováveis se comparado a 2018, além de um aumento na demanda total de 1,4\% no mesmo período (MME, 2020).

Importante destacar que o uso de fontes renováveis - hidráulica, eólica, solar e bioenergia, alcançaram o patamar de $46,1 \%$ na Matriz Energética brasileira ${ }^{5}$.

No contexto mundial, o ano de 2020 apresentou um aumento significativo no uso de fontes renováveis. Em 01 de setembro de 2020, a BloombergNEF (2020) publicou o resultado de uma pesquisa onde $67 \%$ de toda a energia produzida no mundo era proveniente de fontes eólicas e fotovoltaicas.

Verifica-se uma tendência na aplicação de tecnologia para o desenvolvimento de fontes com menor impacto ao meio ambiente e potencialidade equivalente às fontes poluentes.

\footnotetext{
4 "Estes indicadores fazem parte da Resenha Energética Brasileira de 2020, tendo como fonte de dados o Balanço Energético Nacional do ano base 2019 (edição 2020), concluído pela Empresa de Pesquisa Energética, com a cooperação do Ministério de Minas e Energia e as Empresas e Agentes do Setor Energético.” Disponível em http://www.mme.gov.br/todas-as-noticias/-/asset_publisher/pdAS9IcdBICN/content/fontes-renovaveis-sobem-06-ponto-percentual-na-matriz-energetica Acesso em 12 dez 2020.

5 Também conhecida como Matriz da Demanda Total de Energia.
} 


\section{ACORDO DE PARIS: A AGENDA 2030}

Passados cinco anos da realização do Acordo de Paris com a publicação da Agenda 2030 e seus 17 Desafios do Desenvolvimento Sustentável - ODS -, é possível verificar que alguns passos já foram dados.

O documento intitulado Agenda 2030 é fruto da reunião entre líderes dos Estados Membros da ONU que se reuniram em setembro de 2015 com o objetivo de criar um plano de ação para erradicar a pobreza, proteger o planeta e garantir que as pessoas alcancem a paz e a prosperidade (ONU, 2015).

Através do Acordo de Paris, houve a estipulação de 17 desafios a serem seguidos pelos Estados Membros, onde os desenvolvidos contribuiriam para aqueles em estágio anterior alcançarem as metas previstas.

Tendo em vista o escopo da pesquisa tratar sobre meio ambiente como um Direito Humano e, delimitando um pouco mais, sobre as questões energéticas, a abordagem será sobre alguns dos ODS’s ou Objetivos do Desenvolvimento Sustentável.

O documento intitulado "Transformando o Nosso Mundo: A Agenda 2030 para o Desenvolvimento Sustentável" tem por objetivo ser um plano de ação, onde os Estados Membros se comprometem a tomar atitudes desafiadoras a fim de promover o desenvolvimento sustentável (ONU, 2015).

De acordo com a Figura 01, dos 17 ODS's pelo menos três estão relacionados à temática energia renovável: 


\section{Figura 01 - 17 Objetivos do Desenvolvimento Sustentável da ONU}

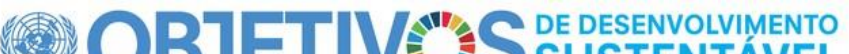
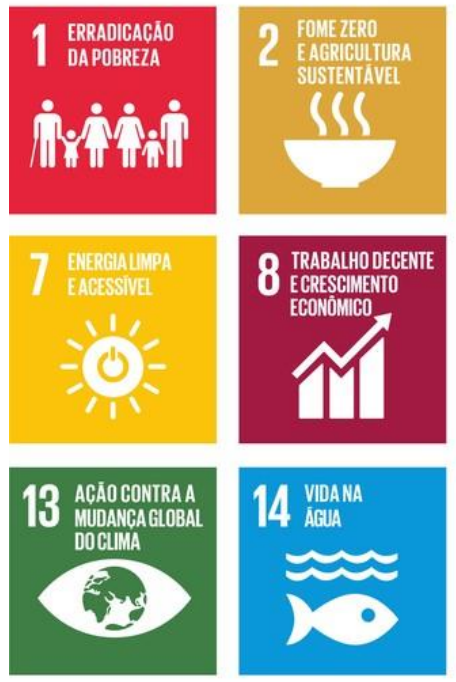
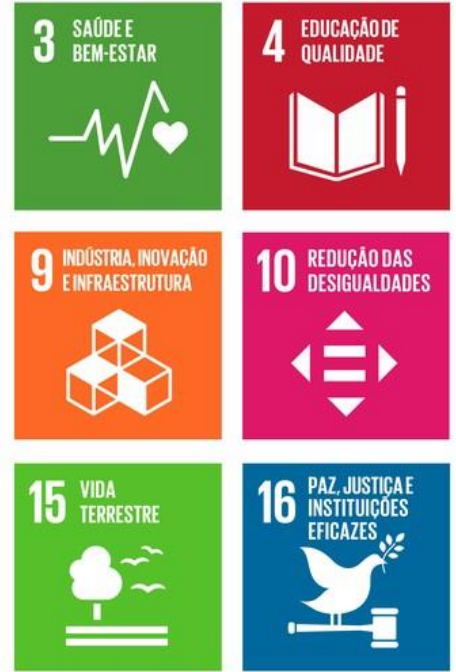

Fonte: ONU (2015)
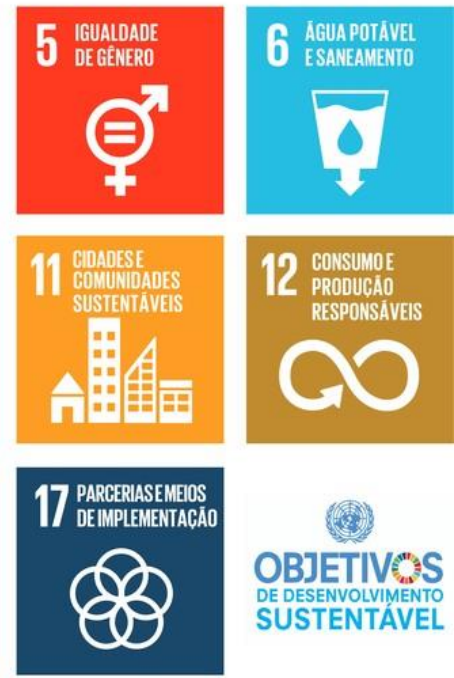

(8)

OBJETIV?S DE DESENVOLVMENENTO

Através de uma breve análise, verifica-se que os ODS’s de números 07 (energia limpa e acessível), 09 (indústria, inovação e infraestrutura), 11 (cidades e comunidades sustentáveis) e 12 (consumo e produção responsáveis) estão relacionados ao tema da pesquisa. Isso reflete a importância da temática e o quão é imprescindível o fomento ao desenvolvimento do setor de energias renováveis em prol da preservação ambiental.

Como apontado por De Carvalho (2018), os atores internacionais são os Estados, responsáveis por buscar maximizar poder e segurança. Isso ocorre por se tratar de uma politica internacional onde os players $^{6}$ buscam adequar a realidade ao mercado.

Vasconcelos (2020) faz uma abordagem sobre os ODS's relacionados à energia renovável, demonstrando a necessidade de estimular o acesso à informação e consumo.

Mediante isso, é possível constatar que as questões energéticas estão diretamente relacionadas ao meio ambiente. Isso pelo fato do impacto causado na emissão de gases de efeito estufa e consequentemente no aquecimento global e sobrevivência da vida no planeta.

\footnotetext{
${ }^{6}$ Players aqui são os Estados-Membros que fazem parte da Organização das Nações Unidas, possuindo papel de extrema relevância na efetivação dos compromissos internacionais.
} 


\section{PLANO CLIMA ENERGIA 2050}

Em 2016 foi elaborado o Plano Nacional de Energia para 2050 (PNE) pelo governo brasileiro. Necessário perfaz lembrar que devido as inúmeras riquezas naturais - sendo inclusive possuidor na maior biodiversidade mundial - como as dimensões continentais, o Brasil possui potencialidade para desenvolver todas as fontes de energia renovável previstas: hidrelétrica, eólica, fotovoltaica e advinda da biomassa (VASCONCELOS, MELLO e VASCONCELOS, 2019).

De acordo com a Empresa Brasileira de Pesquisas Energéticas - EPE -, o PNE prevê uma redução em 35\% no uso de fontes hídricas na matriz energética brasileira. Isso ocorre pelo estímulo na geração de energia por fontes eólicas e fotovoltaicas, levando a uma estimativa do PNE 2050 utilizar aproximadamente 55\% da capacidade instalada advinda de fontes hídricas (CERNE, 2016).

Ressalta-se que o Brasil é um país de fontes renováveis, sendo a sua matriz energética e elétrica majoritariamente limpa (CERNE, 2016).

Todavia, as mudanças nas matrizes não se limitam ao território brasileiro. Em 2019, a União Europeia publica um novo projeto em busca da descarbonização e até mesmo da neutralização na emissão de GEE’s. edita o Pacto Ecológico Europeu - The European Green Deal (EUROPEAN COMISSION, 2019).

Tendo por objetivo tornar a economia da União Europeia (UE) mais sustentável, o Pacto Ecológico Europeu possui três pilares: não emissão líquida de GEE em 2050; crescimento econômico não relacionado a exploração de recursos; e, por fim, que nenhuma região da EU seja deixada ignorada (EUROPEAN COMISSION, 2019, 2).

No que abrange as fontes renováveis, o Pacto Ecológico Europeu, através da proposta de uma Lei Europeia do Clima, tem por objetivo atingir diversos setores da economia. São eles: “...investir em tecnologias não prejudiciais para o ambiente, apoiar a inovação industrial, implantar formas de transporte público e privado mais limpas, mais baratas e mais saudáveis; descarbonizar o setor da energia, assegurar o aumento da eficiência energética dos edifícios, cooperar com parceiros internacionais no sentido de melhorar as normas ambientais globais". Todos diretamente relacionados a área de energia (EUROPEAN COMISSION, 2019, 2).

Acerca do Plano Clima Energia, no contexto europeu, cada Estado Membro desenvolveu o seu plano nacional. Tem-se como exemplo Portugal que, em julho de 2020, publicou o Plano Nacional Integrado de Energia e Clima - o PNEC 2030. O objetivo do programa português é atingir cinco pontos principais: a descarbonização, eficiência energética, segurança de abastecimento, mercado interno da energia e investigação, inovação e competitividade. 
Percebe-se assim um movimento não apenas nacional como mundial em prol de medidas para a melhor proteção e preservação ambiental.

\section{PROJEÇÃO PÓS-PANDEMIA}

O ano de 2020 ficará para sempre marcado na História Mundial. Passados nove meses desde a decretação da pandemia de COVID-19 pela Organização Mundial de Saúde ${ }^{7}$, as questões atinentes ao meio ambiente passaram a ter uma relevância maior.

De acordo com estudos publicados ao longo do ano de 2020, medidas atinentes a preservação e conservação do meio ambiente podem evitar ou estimular o surgimento de novas pandemias. Para pesquisadores da University of Princetown, a ocorrência de destruição de florestas tropicais acrescidos do comércio de animais selvagens, são elementos que podem contribuir significativamente ao surgimento de patógenos com potencial pandêmico (DOBSON et al, 2020).

Em outro estudo publicado na Revista Nature em agosto de 2020, foi constatado que a degradação ambiental contribui significativamente no processo de migração de vírus de pequenos animais para o homem (GIBB et al, 2020).

No contexto das energias renováveis, tendo por base o New Energy Outlook 2020 da BloombergNEF, é possível verificar que há três cenários. O primeiro diz respeito à transição econômica, relacionado ao comportamento do consumidor e uso de tecnologias acessíveis comercialmente. O segundo está relacionado ao aspecto climático. Nesse, é preciso verificar alternativas para redução de gases de efeito estufa através de uso de energia e hidrogênio verde. No terceiro e último cenário, há o aspecto político imprescindível para os cenários anteriores.

De acordo com o Global Trends in Renewable Energy Investment 2020, um estudo feito pelo Programa das Nações Unidas para o Meio Ambiente (PNUMA), do Centro de Colaboração da Escola de Frankfurt da BloombergNEF (BNEF), mostra que fontes renováveis "vem suplantando a participação dominante dos combustíveis fósseis na geração de eletricidade na última década". Com isso, houve um crescimento significativo em fontes eólicas e solares, incentivadas pela economia e tecnologia aplicadas.

O estudo realizado mostra que mesmo com a pandemia da COVID 19, o setor de energias renováveis vem apresentando um crescimento significativo. O próprio relatório Global Trends mostra a tendência a novos investimentos em prol do aumento da participação das fontes com menor impacto ao meio ambiente.

7 OMS afirma que COVID-19 é agora caracterizada como pandemia. Disponível em https://www.paho.org/bra/index.php?option=com_content \&view=article\&id=6120:oms-afirma-que-covid-19-eagora-caracterizada-como-pandemia\&Itemid=812 Acesso em $12 \mathrm{dez} 2020$. 
É preciso verificar que as questões atinentes ao meio ambiente precisam mais do que nunca ser discutidas e as políticas efetivadas, de forma a não apenas alcançar o desenvolvimento sustentável e o cumprimento das políticas internacionais. A questão núcleo em 2020 passa a ser desenvolver e sobreviver, sem o risco iminente de novas pandemias em curto ou médio prazo.

\section{CONSIDERAÇÕES FINAIS}

Toda e qualquer questão atinente ao meio ambiente deve ser vista como um Direito Humano. Isso ocorre não pela sua categorização $-3^{\mathrm{a}}$. dimensão ou geração - mas pela essencialidade e importância a sobrevivência da vida.

Durante a pesquisa foi possível verificar que os tratados e acordos internacionais possuem um papel relevante em busca do desenvolvimento sustentável. A efetivação das políticas internacionais por todos os países impactam de forma direta na realidade das sociedades.

Isso inclui as questões energéticas, principalmente o uso das tecnologias disruptivas ou novas tecnologias em prol do desenvolvimento daquelas tidas como renováveis. Através dos avanços tecnológicos é possível um menor impacto na atmosfera, buscando uma descarbonização e até mesmo a neutralização na emissão de gases de efeito estufa.

Todavia, mais do que nunca e influenciado pelo impacto que a pandemia da COVID 19 trouxe, é preciso uma mudança comportamental na sociedade e nos gestores. Essa atitude está voltada à medidas de preservação e não degradação ambiental, sendo imprescindível que os atos estejam em conformidade às políticas internacionais.

Trata-se mais do que nunca de questão de sobrevivência e de efetivação os Direitos Humanos.

\section{REFERÊNCIAS}

ATHAÝDE, Austragésilo de; IKEDA, Dausaku. Diálogo Direitos Humanos no século 21. Edição comemorativa do $25^{\circ}$ aniversário do encontro dos autores. Brasil Seikyo: São Paulo, 2018

BLOOMBERGNEF. Solar and Wind Reach 67\% of New Power Capacity Added Globally in 2019, while Fossil Fuels Slide to 25\%. Disponível em https://about.bnef.com/blog/solar-andwind-reach-67-of-new-power-capacity-added-globally-in-2019-while-fossil-fuels-slide-to-25/ Acesso em 09 set 2020. 
BLOOMBERGNEF. New Energy Outlook 2020. Disponível em https://about.bnef.com/newenergy-outlook/ Acesso em $12 \mathrm{dez} 2020$.

BLOOMBERGNEF. Global Trends in Renewable Energy Investment 2020. Disponível em https://www.fs-unep-centre.org/global-trends-in-renewable-energy-investment-2020/ Acesso em 08 dez 2020.

BRASIL. Constituição da República Federativa do Brasil. Promulgada em 10 de outubro de 1988. Disponível em http://www.planalto.gov.br/ccivil_03/constituicao/constituicao.htm. Acesso em 12 dez 2020.

BRASIL. Política Nacional de Conservação e Uso Racional de Energia. LEI ${ }^{\circ} 10.295$ de 17 de outubro de 2001. Disponível em http://www.planalto.gov.br/ccivil_03/leis/leis_2001/110295.htm Acesso em 12 dez 2020.

CERNE. Centro de Estudos Naturais e Energia. Brasil é campeão em energia limpa. Disponível em <http://cerne.org.br/brasil-e-campeao-em-energia-limpa/> Acesso em: 02 dez 2020.

CERNE. Centro de Estudos Naturais e Energia. Consumo de renováveis vai crescer 4,8\% ao ano até 2035. Disponível em <http://cerne.org.br/consumo-de-renovaveis-vai-crescer-48-aoano-ate-2035/> Acesso em: $02 \mathrm{dez} 2020$.

DE CARVALHO, Francisco Tonilo. A Agenda 2030 para o Desenvolvimento Sustentável da ONU e seus Atores: o impacto do desenvolvimento sustentável nas relações internacionais. Confluências. ISSN 2318-4558. V. 21, n.3, 2019. Publicado em dezembro 2019. P. 5-19. Disponível em https://periodicos.uff.br/confluencias/article/view/34665/22955 Acesso em 10 $\operatorname{dez} 2020$.

DOBSON, Andrew P., PIMM ,Stuart L., HANNAH, Lee, KAUFMAN ,Les, AHUMADA , Jorge A., ANDO ,Amy W., BERNSTEIN , Aaron, BUSCH, Jonah, DASZAK, Peter, ENGELMANN, Jens, KINNAIRD ,Margaret F., LI, Binbin V., LOCH-TEMZELIDES, Ted, LOVEJOY, Thomas, NOWAK, Katarzyna, ROEHRDANZ, Patrick R., Mariana M. ValeEcology and economics for pandemic prevention. Publicado em 24 Jul 2020: Science. $\begin{array}{lllll}\text { Vol. } & \text { 369, } & \text { Issue } & 6502, & \text { 379-381 }\end{array}$ DOI: $\quad 10.1126 /$ science.abc3189. Disponível em https://science.sciencemag.org/content/369/6502/379 Acesso em 12 dez 2020.

EUROPEAN COMISSION. Estratégia a longo prazo para 2050. Disponível em https://ec.europa.eu/clima/policies/strategies/2050_pt. Acesso em 12 dez 2020.

EUROPEAN COMISSION. The European Green Deal. Disponível em https://ec.europa.eu/info/strategy/priorities-2019-2024/european-green-deal_en Acesso em 12 $\operatorname{dez} 2020$. 
FIORILlO, Celso Antônio P. Princípios do Direito Processual Ambiental. São Paulo. Ed. Saraiva. 6a . ed. 2016.

GIBB, Rory; Redding, David W., Chin, Kai Qing, Donnelly, Christl A., Blackburn ,Tim M., Newbold, Tim, . Jones, Kate E. Zoonotic host diversity increases in human-dominated ecosystems. Nature. 584, pages398-402(2020). Publicado em 05 de agosto de 2020. Disponível em https://www.nature.com/articles/s41586-020-2562-8. Acesso em 10 set 2020.

MINISTERIO DE MINAS E ENERGIA. Fontes renováveis sobem 0,6 ponto percentual na Matriz Energética. Publicado em 20 de julho de 2020. Disponível em http://www.mme.gov.br/todas-as-noticias/-/asset_publisher/pdAS9IcdBICN/content/fontesrenovaveis-sobem-0-6-ponto-percentual-na-matriz-energetica Acesso em 12 dez 2020.

ONU. Organização das Nações Unidas. Report of the United Nations Conference on the Human Environment. Publicada em 05 de junho de 1972. Disponível em http://www.undocuments.net/aconf48-14r1.pdf. Acesso em 12 dez 2020.

ONU. Organização das Nações Unidas. Plataforma Agenda 2030. A Agenda 2030 para o Desenvolvimento Sustentável. 2015. Disponível em http://www.agenda2030.com.br/sobre/ Acesso em 10 dez 2020.

OPAS BRASIL. Organização Pan-Americana da Saúde. OMS afirma que COVID-19 é agora caracterizada como pandemia. Disponível em https://www.paho.org/bra/index.php?option=com_content\&view=article\&id=6120:omsafirma-que-covid-19-e-agora-caracterizada-como-pandemia\&Itemid=812 Acesso em $12 \mathrm{dez}$ 2020.

PORTUGAL ENERGIA. PNEC 2030. Disponível em https://www.portugalenergia.pt/ Acesso em 02 set 2020.

SIRVINSKAS, Luís Paulo. Manual de direito ambiental. 13 ed. São Paulo: Saraiva, 2015.

VASCONCELOS, Priscila E. A. Responsabilidade Jurídico Ambiental das Usinas Sucroenergéticas e a Recuperação de Áreas Degradadas. Processo: Rio de Janeiro, 2019.

VASCONCELOS, Priscila E. A. A Função Socioambiental das Cidades. O uso de energias renováveis e a cogeração advinda de resíduos agroindustriais. Processo: Rio de Janeiro, 2020.

VASCONCELOS, Priscila E.A.; MELLO, Cleyson de Moraes; VASCONCELOS, Paulo S. $O$ Incentivo Ao Uso De Energias Renováveis Como Forma De Preservação Ambiental E $O$ Princípio Constitucional Da Dignidade Da Pessoa Humana. In: Democracia e Direitos Fundamentais. Estudos em Homenagem ao Professor Leonardo Rabelo. Processo: Rio de Janeiro, 2019. 